\title{
Correlates of Age at Initial Diagnosis of Chronic Lymphocytic Leukemia: Exercise, ASA \& Emotional Distress
}

\author{
Mark W. Ketterer, Emily A. Ketterer, Bernd Barthel, Phillip Kuriakose, Amr Hanbali, Yue Guo, \\ Walter Knysz \\ Consultation/Liaison Psychiatry \& Josephine Ford Cancer Center Henry Ford Hospital, Detroit, MI, USA \\ Email: MKetter1@hfhs.org
}

Received February 13, 2012; revised March 8, 2012; accepted March 15, 2012

\begin{abstract}
Objective: No studies of either the cross-sectional or prospective association of behavioral lifestyle characteristics and the onset of Chronic Lymphocytic Leukemia (CLL) exist. Methods: Multiple interview or questionnaire measures of emotional distress and social support, as well as personality characteristics, exercise, sleep quality, aspirin or lipid-lowering medication use, smoking status and history, educational history and farming/pesticide exposure were tested as correlates of age at initial diagnosis of CLL (AAID-CLL) in 183 patients recruited from the electronic records of Henry Ford Hospital or internet support sites. Results: Aspirin use, having always been "Fit" and living alone were positively associated with AAID. Negative associations were observed for farming/pesticide exposure, years of education, being married, self description as a "Lone Wolf” or "Worrier", taking "nerve” or "sleeping” pills, awakenings per night, Packyears of Smoking and the Interpersonal Sensitivity, Depression, Anxiety, Hostility and Paranoia scales of the Symptom Checklist 90 - Revised, as well as the AIAI (anger), Depression and Anxiety scales of the Spouse/Friend Ketterer Stress Symptom Frequency Checklist. Conclusions: Aspirin use and exercise may exert a modifiable delaying influence in the onset of CLL. Conversely, emotional distress and smoking may hasten its onset. Prospective, and interventional, tests of these findings are needed.
\end{abstract}

Keywords: Chronic Lymphocytic Leukemia; Stress; Aspirin

\section{Background}

Recognized risk factors for the initiation of CLL include: certain chemical exposures (Agent Orange, pesticides/ farming), family history of CLL, male sex and Euroamerican derivation [1]. Surprisingly, we can locate no studies examining lifestyle behaviors as predictors of disease onset, other than smoking. However, a few papers are available on "quality-of-life" in CLL patients. Because quality of life is strongly confounded with emotional distress, these studies may provide some insight regarding the impact of distress on CLL onset.

CLL patients report poorer emotional/social qualityof-life than age/gender matched controls, and female CLL patients report poorer social/emotional quality-oflife than males [2-5]. While these findings might be interpreted as the result of having CLL, several findings contradict this hypothesis:

1) Self-reported quality-of-life measures (including emotional distress) were not dramatically different between patients at the "watch and wait" stage for CLL versus those undergoing active treatment; and 2) Newly diagnosed patients were not more distressed than those diagnosed an average of six years previously [6].

If having CLLwere a cause of diminished qualityof-life, then later stage patients might have been expected to be worse off than earlier stage patients.

Emotional Distress (ED) may impact cellular "aging” (telomerase levels and telomere length) and DNA repair capacity (Host-Cell Reaction Assay) mechanisms [7-10]. ED has repeatedly been demonstrated to adversely impact immune functioning [11]. At least one study on qualityof-life in CLL indicates that patients who are emotionally distressed are more likely to drop out of prospective investtigations [2]. It is not clear whether these higher dropout rates are merely behavioral sequelae of the emotional distress (a common finding in other distressed medical populations), or due to more rapid disease progression and/or higher death rates. If the latter is true, then a potential new means of influencing disease progression may be implied.

To date, studies of emotional distress and quality-of-life in CLL have used only self-report measures. Because of 
the obfuscating impact of denial/minimization, several investigators have demonstrated superior cross-sectional and prospective predictive power of significant other ratings of emotional distress in several medical populations [12-19]. Social Isolation/Alienation [20], Sleep Quality [21] and Exercise [22,23] are known correlates of ED and thus may be of interest. Exercise has also been found to be a correlate of slowed cellular aging [24].

ASA use appears to affect emotional distress [25], and may protect against some forms of cancer [26] including CLL, at least in females [27]. This relationship is now known to be causal for some cancers by re-analysis of randomly-assigned, controlled ASA trials initially conducted to assess the impact on coronary heart disease [28]. Smoking has been reported not to influence CLL, and we are aware of no studies that examine ETOH use and CLL onset/progression. Spontaneously low lipids, and lipid-lowering have been found to be associated with cancers. While spontaneously low lipids may reflect previously undiagnosed cancer, the compensatory rise in cancer (reflected in a lower CHD mortality but NO change in overall mortality rate) with induced lipid-lowering $[29,30]$ cannot. To date, it is unclear which cancers may be influenced by low or lowered lipids.

Occupational exposure to pesticides or other chemicals may be related to CLL onset $[31,32]$.

The purpose of the present paper is to study various lifestyle behaviors (emotional distress, social isolation/alienation, sleep quality, exercise, personality, alcohol use, smoking, occupational exposure and selected chronic medications) as correlates of age at initial diagnosis for CLL.

\section{Methodology}

\subsection{Subjects}

The sample initially consisted of 198 patients with Chronic Lymphocytic Leukemia recruited from the patient population at Henry Ford Hospital, or internet patient support sites like http://CLLTopics.org.Alert/aler-treg.php, Listserv @Listserv.ACOR.ORG, and the Leukemia \& Lymphoma Society Bulletin Board for CLL. Fifteen patients subsequently withdrew after receiving the mailed packets, leaving a residual sample of 183; 77 from the HFH population (42\%) and 106 recruited via the Internet (58\%). Three of the dropouts indicated they were concerned that their data might end up with their insurance company (a possibility listed in the written Consent Form), and three indicated they considered the questions to be "stupid". The remaining nine patients gave no reason for withdrawing. Average age was: $66.2(\mathrm{SD}=10.7)$. Average years of education was 14.5 (3.7). Average years since diagnosis was 5.7. The proportion of females was 55\% (101/183). The proportion of patients who had experienced chemotherapy was $49 \%$ (80/183).
The patients recruited through HFH were less likely: to characterize themselves as "worriers" (42\% vs $55 \%$, Chi-Square $=3.09, \mathrm{p}=0.027)$; to be married $(52 \%$ vs $77 \%$, Chi-Square $=12.86, \mathrm{p}<0.001$ ), but more likely to live alone ( $34 \%$ vs $19 \%$, Chi-Square $=5.26, \mathrm{p}=0.085)$; be older (70.6 years vs 63.1 years, $t=-5.0, p<0.001$ ); have a later age at initial diagnosis (64.1 years vs 57.9 years, $\mathrm{t}=-3.88$, $\mathrm{p}<0.001)$; have fewer years of education (12.4 years vs 16.0 years, $\mathrm{t}=7.4, \mathrm{p}<0.001$ ); report fewer nights per week with nocturnal awakening (1.4 vs $2.0, \mathrm{t}=1.7, \mathrm{p}=0.049)$; fewer mornings per week awakening tired (1.8 mornings vs 3.2 mornings, $t=3.18, \mathrm{p}=$ $0.001)$; have fewer drinks per week (1.5 drinks vs 3.1 drinks, $\mathrm{p}=2.19, \mathrm{p}=0.015$ ) and later age at initial diagnosis (64.1 years vs 57.9 years, $t=-3.88, \mathrm{p}<0.001$ ). Thus our Internet recruited sample appears to have been younger, younger at diagnosis, better educated and more distressed than our in-house patient sample.

The number of patients returning the SCL90R by mail was 101. The number having the Spouse/Friend Version of the KSSFC returned by mail was 103. Compared to nonreturnees, patients who returned the SCL90R were more likely to endorse being a worrier $(55.4 \%$ versus $41.5 \%$, Chi-Square $=3.54, \mathrm{p}=0.041$ ), having a confidante (87.1\% versus $75.6 \%$, Chi-Square $=4.06, \mathrm{p}=0.034)$, and took less time to fall asleep at night (28.0 versus 64.8 minutes, $\mathrm{t}=1.61, \mathrm{p}=0.055$ ).

\subsection{Instruments}

The interview used was semi-structured and consisted of demographic/clinical information (age, education, age at initial diagnosis, etc.), personality characteristics ("Are you a Worrier?”, “Are you a Lone Wolf?”, etc.), sleep quality ("On average, when you turn out the lights and put your head on the pillow, how long does it take you to fall asleep?”, etc.) and questions derived from the published literature on such characteristics as farming/pesticide exposure and aspirin use. If a patient hesitated on a yes-no query about personality characteristics, he/she was further prompted by asking: "Compared to most people you know, would you say you are...?” If a patient hesitated on the queries about sleep parameters, he/she was further prompted by asking: "Over the last week, how many nights have you...?”

The Symptom Checklist 90 - Revised is a widely known and used omnibus measure of self-reported emotional distress [33].

The Spouse/Friend version of the Ketterer Stress Symptom Frequency Checklist is the only available normed, validated and standardized measure of emotional distress written to be completed by a spouse or friend [34,35].

\subsection{Procedures}

HFH patients were contacted initially by phone with per- 
mission of their Hematologist/Oncologist. Internet support site participants were solicited for contact information with the permission of site moderators. Initial phone contacts described the study and obtained verbal assent to proceed to the initial interview. Mailings followed with written instructions on: completing a written consent form; obtaining permission for obtaining medical records at a later date; completion of the SCL90R and return in a stamped, addressed envelope; and instructions to have "someone who knows you well" complete and return the Spouse/Friend KSSFC.

\subsection{Analyses}

The $\mathrm{p}<0.05$, one-tailed criterion was used. The patients recruited from $\mathrm{HFH}$ were compared with the Internet recruited subjects on age, years of education, clinical history and the sleep quality and personality characteristics. These results are discussed above in the "Subjects" subsection.

Nonreturnees for the SCL90R were compared with returnees on the same parameters. These results are also discussed in the "Subjects" subsection.

Inferential univariate tests of association (Pearson Product-Moment Correlation Coefficients \& Student's T-Test, depending upon the nominal versus ordinal/interval/ration status of the independent variable) were run between the age at initial diagnosis of CLL, and the clinical/demographic/personality/sleep and psychometric variables.

Finally, in those subgroups of patients who returned the SCL90R $(\mathrm{N}=101)$ and the Spouse/Friend KSSFC (N = 103), univariate tests for AAID for CLL were run.

\section{Results}

Younger AAID was associated with: self acknowledgement of being a "Worrier" or a "Lone Wolf"; being married; taking pills for "nerves” or "sleep”; exposure to farming/pesticides; reporting more unprovoked awakenings per night; more years of education; higher scores on the Interpersonal Sensitivity, Depression, Anxiety, Hostility and Paranoia scales of the SCL90R; as well as higher scores on the AIAI, Depression and Anxiety scales of the Spouse/Friend KSSFC. Older AAID was associated with: living alone; having always been "Fit"; and taking ASA. These results are contained in Tables $\mathbf{1}$ and 2.

\section{Discussion}

The heterogeneous nature of our sample may have produced some artifactual findings, notably the negative association of AAID for CLL with Years of Education and Hours of Exercise per week. None the less, our confirmation of findings reported by others (for ASA use and Farming/Pesticide exposure) gives us confidence that our results deserve serious scrutiny.
Table 1. Interview data for AAID in 183 patients with CLL. Age at Initial Diagnosis of CLL compared across yes-no groupings, and correlated with continuous variables.

\begin{tabular}{|c|c|c|c|c|}
\hline T-Tests & Yes & No & $\mathrm{t}$ & $\mathrm{p}$ \\
\hline \multirow[t]{3}{*}{ Are you a Worrier? } & 59.2 & 61.8 & 1.57 & 0.059 \\
\hline & $(11.5)$ & $(10.7)$ & & \\
\hline & 90 & 93 & & \\
\hline \multirow[t]{3}{*}{ Are you a Lone Wolf? } & 58.4 & 61.9 & 2.13 & 0.018 \\
\hline & $(10.5)$ & $(11.4)$ & & \\
\hline & 74 & 109 & & \\
\hline \multirow[t]{3}{*}{ Are you Married? } & 59.5 & 62.5 & 1.72 & 0.044 \\
\hline & (9.9) & $(13.1)$ & & \\
\hline & 122 & 61 & & \\
\hline \multirow[t]{3}{*}{ Do you Live Alone? } & 63.2 & 59.6 & -1.92 & 0.028 \\
\hline & $(12.2)$ & $(10.7)$ & & \\
\hline & 46 & 137 & & \\
\hline \multirow[t]{3}{*}{ Have you always been Fit? } & 61.2 & 57.7 & -1.71 & 0.045 \\
\hline & $(11.4)$ & (9.5) & & \\
\hline & 147 & 36 & & \\
\hline \multirow{3}{*}{$\begin{array}{l}\text { Do you take pills for "nerves" or } \\
\text { "sleep"? }\end{array}$} & 58.7 & 61.6 & 1.66 & 0.050 \\
\hline & $(10.3)$ & (11.5) & & \\
\hline & 68 & 115 & & \\
\hline \multirow[t]{3}{*}{ Do you take a daily Aspirin? } & 63.2 & 59.3 & -2.23 & 0.014 \\
\hline & $(10.4)$ & $(11.3)$ & & \\
\hline & 57 & 126 & & \\
\hline \multirow{3}{*}{$\begin{array}{l}\text { Were you exposed to } \\
\text { Farming/Pesticides? }\end{array}$} & 56.1 & 61.4 & 2.48 & 0.007 \\
\hline & $(13.0)$ & $(10.6)$ & & \\
\hline & 32 & 151 & & \\
\hline
\end{tabular}

Nonsignificant Queries:

Are you a Perfectionist?

Do you have a Temper? $(p=0.095)$

Are you Lonely?

Are you Shy?

Do you have a Confidant? $(\mathrm{p}=0.071)$

Are you a Light Sleeper?

Are you Currently Smoking? $(p=0.061)$

Do you take pills for Cholesterol? $(\mathrm{p}=0.086)$

Have you ever done Lab Work?

Have you ever been exposed to Radiation at work?

\begin{tabular}{ccc}
\hline Pearson r $(\mathrm{N}=182)$ & $\mathrm{r}$ & $\mathrm{p}$ \\
\hline Sleep Onset: & -0.019 & 0.399 \\
Number of Awakenings: & -0.138 & $0.032^{*}$ \\
Awakening Tired: & -0.092 & 0.186 \\
PackYears of Smoking: & 0.031 & 0.388 \\
Years of Education: & -0.225 & $0.001^{*}$ \\
Drinks/Day: & -0.079 & 0.143 \\
Hours of Exercise: & -0.214 & $0.002^{*}$ \\
\hline
\end{tabular}


Table 2. The association of AAID for CLL with Symptom Checklist 90 - Revised scales in 101 patients with CLL.

\begin{tabular}{lcc}
\hline & $\mathrm{r}$ & $\mathrm{p}$ \\
\hline Interpersonal Sensitivity: & -0.267 & 0.004 \\
Depression: & -0.206 & 0.020 \\
Anxiety: & -0.271 & 0.003 \\
Hostility: & -0.265 & 0.004 \\
Paranoia: & -0.221 & 0.013 \\
GSI: & -0.184 & 0.033 \\
PSDI: & -0.185 & 0.032 \\
\hline The association of AAID for CLL with Spouse/Friend Ketterer Stress \\
Symptom Frequency Checklist scales in 103 CLL patients. \\
\hline
\end{tabular}

Our dependent variable, age at initial diagnosis of CLL, may or may not carry implications for long term management of diagnosed CLL but is presumably strongly correlated with the age at which CLL is initiated. CLL is assumed to be initiated by a mutagenic event which fails to be lysed by cellular or subcellular maintenance/repair or immunological processes. Thus association of a potential risk factor with early AAID-CLL may reflect increased: 1) likelihood of early detection (e.g., higher educational attainment causing better insurance status or greater health consciousness and more assertive patient followup), 2) greater exposure to mutagenic risk (e.g., farming/pesticide exposure), or 3) failure of cellular monitoring/ maintenance/repair/proliferative processes, or all three. The last of these possibilities is the most exciting because the independent predictors of AAID-CLL may reflect controllable events with the possibility of influencing the onset of the illness.

Present results replicate previous studies in finding that farming/pesticide exposure [31,32,36] and ASA use [27] may have beneficial effects for the onset of CLL. While early life pesticide exposure is not reversible, ASA use clearly is for most patients. It is difficult to conceive of a well executed controlled clinical trial of ASA since it is universally available and patients agreeing to participate in such a trial would be tempted to dose themselves. None the less, naturalistic studies of patients who are "spontaneously" taking ASA and following disease progression seem feasible and potentially enlightening.

Exercise has not previously been investigated as a factor in onset of illness for CLL. Our patients who reported themselves as having always been "Fit" had later diagnosis of CLL, but reported Hours of Exercise per Week was negatively related to age at initial diagnosis-an apparent paradox and, perhaps, an artifact of our sample sources. Like ASA, naturalistic observation of "spontaneously" occurring exercise and course of illness seems feasible, while a controlled clinical trial would also be difficult to execute because of patient compliance.

Perhaps most impressive among our findings is the observation that multiple measures of emotional distress are associated with earlier onset CLL. It has been known for several decades now that some measures of ED are associated with suppression of some immune parameters [11]. More recently, ED has been implicated as a cause of diminished telomerase levels [10], telomere shortening [8] and diminished DNA repair capacity [7,9]. Because of the complexity of both the psychoneuroendocrine and immunological systems, other possible mechanisms may remain to be discovered. Because knowledge of mechanisms is unnecessary, although reassuring, for the clinician [37], advancements in clinical research can proceed unimpeded by the mechanism conundrum. Our results may imply four new avenues for delaying the onset of CLL: ASA use, being "Fit", smoking avoidance and treatment of ED. Given the widely recognized safety of these potential therapies, we believe prospective clinical observation studies and, more credibly, clinical trials should be considered.

Present results must be interpreted in the context of the limitations of our methods. For practical reasons (i.e., pursuit of a meaningful sample size), our patient sources were mixed, with one source (internet recruited) not permitting independent checking of records to affirm the patient's report. It is likely some error was introduced into our dataset by this method, although we cannot determine how much. But is it likely to be systematic error that would have biased our results in favor of our findings? We think not. Future work should strive to independently ascertain CLL diagnosis and WBCs. In addition, present results need confirmation in a prospective study or, better still, intervention study(s). The latter is the only true experiment in risk factor research and the "gold standard" for determining causality [37].

\section{REFERENCES}

[1] American Cancer Society, "What Are the Risk Factors for Chronic Lymphocytic Leukemia?” 2007. www.cancer.org

[2] B. Holzner, G. Kemmler, M. Koop, D. Nguyen-Van-Tem, B. Sperner-Unterweger and R. Greil, "Quality of Life of Patients with Chronic Lymphocytic Leukemia Results of a Longitudinal Investigation over 1 Year,” European Journal of Haematology, Vol. 72, No. 6, 2004, pp. 381389. doi:10.1111/j.1600-0609.2004.00233.x 
[3] T. D. Shanafelt, D. Bowen, C. Venkat, S. L. Slager, C. S. Zent, N. E. Kay, M. Reinalda, J. A. Sloan and T. G. Call, "Quality of Life in Chronic Lymphocytic Leukemia: An International Survey of 1482 Patients,” British Journal of Haematology, Vo. 139, No. 2, 2007, pp. 255-264. doi:10.1111/j.1365-2141.2007.06791.x

[4] M. Else, A. G. Smith, K. Cocks, S. M. Richards, S. Crofts, R. Wade and D. Catovsky, "Patients' Experience of Chronic Lymphocytia Leukemia: Baseline Health-Related Quality of Life Results from the Lrf CLL4 Trial," British Journal of Haematology, Vol. 143, No. 5, 2008, pp. 690697. doi:10.1111/j.1365-2141.2008.07407.x

[5] B. F. Eichhorst, R. Busch, T. Obwundner, I. Kuhn-Hallek, P. Herschbach and M. Hallek, "Health-Related Quality of Life in Younger Patients with Chronic Lymphocytic Leukemia Treated with Fludarabine Plus Cyclophosphamide or Fludarabine Alone for First-Line Therapy: A Study by the German CLL Study Group," Journal of Clinical Oncology, Vol. 25, No. 13, 2007, pp. 1722-1731. doi:10.1200/JCO.2006.05.6929

[6] T. T. Levin, Y. Li, J. Riskind and K. Rai, "Depression, Anxiety and Quality of Life in a Chronic Lymphocytic Leukemia Cohort," General Hospital Psychiatry, Vol. 29, No. 3, 2007, pp. 251-256. doi:10.1016/j.genhosppsych.2007.01.014

[7] L. Cohen, G. D. Marshall, L. Cheng, S. K. Agarwal and Q. Wei, "DNA Repair Capacity in Healthy Medical Students during and after Exam Stress," Journal of Behavioral Medicine, Vol. 23, No. 6, 2000, pp. 531-544. doi:10.1023/A:1005503502992

[8] E. S. Epel, E. H. Blackburn, J. Lin, F. S. Dhabhar, N. E. Adler, J. D. Morrow and R. M. Cawthorn, "Accelerated Telomere Shortening in Response to Life Stress," Proceedings of the National Academy of Sciences, Vol. 101, No. 49, 2004, pp. 17312-17315. doi:10.1073/pnas.0407162101

[9] J. K. Kiecolt-Glaser, R. E. Stephens, P. D. Lipetz, C. E. Speicher and R. Glaser, "Distress and DNA Repair in Human Lymphocytes,” Journal of Behavioral Medicine, Vol. 8, No. 4, 1985, pp. 311-320. doi:10.1007/BF00848366

[10] D. Ornish, J. Lin, J. Daubenmier, G. Weidner, E. Epel, C. Kemp, M. J. M. Magbanua, R. Marlin, L. Yglesias, L. Carroll and E. H. Blackburn, "Increased Telomerase Activity and Comprehensive Lifestyle Changes: A Pilot Study," Lancet: Oncology, Vol. 10, No. 11, 2008, pp. 1048-1057.

[11] R. Ader, "Psychoneuroimmunology," 4th Edition, Academic Press, New York, 2006.

[12] M. W. Ketterer, J. Brymer, K. Rhoads, P. Kraft, L. Kenyon, B. Foley, W. R. Lovallo and C. J. Voight, "Emotional Distress among Males with 'Syndrome X', Journal of Behavioral Medicine, Vol. 19, No. 5, 1996, pp. 455-466. doi:10.1007/BF01857678

[13] M. W. Ketterer, L. Kenyon, B. A. Foley, J. Brymer, K. Rhoads, P. Kraft P and W. R. Lovallo, "Denial of Depression as an Independent Correlate of Coronary Artery Disease,” Journal of Health Psychology, Vol. 1, No. 1, 1996, pp. 93-105. doi:10.1177/135910539600100108
[14] M. W. Ketterer, J. Huffman, M. A. Lumley, S. Wassef, L. Gray, L. Kenyon, P. Kraft, J. Brymer, K. Rhoads, W. R. Lovallo and A. D. Goldberg, "Five-Year Follow-up for Adverse Outcomes in Males with at Least Minimally Positive Angiograms: Importance of 'Denial' in Assessing Psychosocial Risk Factors,” Journal of Psychosomatic Research, Vol. 44, No. 2, 1998, pp. 241-250. doi:10.1016/S0022-3999(97)00206-7

[15] M. W. Ketterer, J. Denollet, J. Chapp, S. Keteyian, A. J. Farha, V. Clark, M. Hudson, A. Hakim, A. Greenbaum, J. Schairer and J. J. Cao, "Men Deny and Women Cry, but Who Dies? Do the Wages of 'Denial' Include Early Ischemic Coronary Heart Disease,” Journal of Psychosomatic Research, Vol. 56, No. 1, 2004, pp. 119-123. doi:10.1016/S0022-3999(03)00501-4

[16] M. A. Lumley, J. L. Huffman, L. J. Rapport, S. K. Aurora, L. Norris and M. W. Ketterer, "Do Others Really Know Us Better? Predicting Migraine Activity from Self- and Other-Ratings of Negative Affect," Journal of Psychosomatic Research, Vol. 58, No. 3, 2005, pp. 253-258. doi:10.1016/j.jpsychores.2004.09.005

[17] R. C. Kneip, A. M. Delamater, T. Ismond, C. Milford, L. Salvia and D. Schwartz, "Self and Spouse Ratings of Anger and Hostility as Predictors of Coronary Heart Disease," Health Psychology, Vol. 12, No. 4, 1993, pp. 301302. doi:10.1037/0278-6133.12.4.301

[18] A. W. Siegman, S. T. Townsend, R. S. Blumenthal, J. D. Sorkin and A. C. Civelek, "Dimensions of Anger and CHD in Men And Women: Self Ratings Versus Spouse Ratings,” Journal of Behavioral Medicine, Vol. 21, No. 4, 1998, pp. 315-336. doi:10.1023/A:1018725212562

[19] T. W. Smith, B. N. Uchino, C. A. Berg, P. Florsheim, G. Pearce, M. Hawkins, P. N. Hopkins and H.-C. Yoon, "Hostile Personality Traits and Coronary Artery Calcification in Middle-Aged and Older Couples: Different Effects for Self-Reports versus Spouse Ratings,” Psychosomatic Medicine, Vol. 69, No. 5, 2007, pp. 441-448.

[20] M. W. Ketterer, W. Knysz, M. Hudson, S. J. Keteyian and A. J. Farha, "Healthcare Utilization \& Emotional Distress in Cad Patients,” Psychosomatics, Vol. 51, No. 4, 2010, pp. 297-301. doi:10.1176/appi.psy.51.4.297

[21] American Sleep Disorders Association, “The International Classification of Sleep Disorders,” 1990. http://www.esst.org/adds/ICSD.pdf

[22] L. D. Dugmore, R. J. Tipson, M. H. Phillips, “Changes in Cardiorespiratory Fitness, Psychological Wellbeing, Quality of Life and Vocational Status Following a 12 Month Cardiac Exercise Rehabilitation Programme,” Heart, Vol. 81, No. 4, 1999, pp. 359-366.

[23] R. V. Milani, C. J. Lavie, M. M. Cassidy, "Effects of Cardiac Rehabilitation and Exercise Training Programs on Depression in Patients after Major Coronary events," American Heart Journal, Vol. 132, No. 4, 1996, pp. 726732. doi:10.1016/S0002-8703(96)90304-X

[24] L. F. Cherkas, J. L. Hunkin, et al., "The Association between Physical Activity in Leisure Time and Leukocyte Telomere Length,” Archives of Internal Medicine, Vol. 168, No. 2, 2008, pp. 154-158. doi:10.1001/archinternmed.2007.39 
[25] M. W. Ketterer, J. Brymer, K. Rhoads, P. Kraft and W. R. Lovallo. "Is Aspirin, as Used for Anti-Thrombosis, an Emotion-Modulating Agent?” Journal of Psychosomatic Research, Vol. 40, No. 1, 1996, pp. 53-58. doi:10.1016/0022-3999(95)00524-2

[26] K. S. Choe, P. R. Cowan, et al., "Aspirin Use and the Risk of Prostate Cancer Death in Men Treated with Prostatectomy or Radiotherapy: Results from the Capsure Database,” International Journal of Radiation Oncology, Biology, Physics, Vol. 78, No. 3, 2010, pp. 126-127.

[27] C. M. Kasum, C. K. Blair, A. R. Folsom and J. A. Ross, "Non-Steroidal Anti-Inflammatory Drug Use and Risk of Adult Leukemia,” Cancer Epidemiology, Biomarkers \& Prevention, Vol. 12., No. 6, 2003, pp. 534-537.

[28] P. M. Rothwell, M. Wilson, C.-E. Elwin, B. Norving, A. Algra, C. P. Warlow and T. W. Meade, "Long-Term Effect of Aspirin on Colorectal Cancer Incidence and Mortality: 20-Year Follow-up of Five Randomized Trials," The Lancet, Vol. 376, No. 9754, 2010, pp. 1741-1750. doi:10.1016/S0140-6736(10)61543-7

[29] M. Pigrone, C. Phillips and C. Mulrow, "Use of LipidLowering Drugs for Primary Prevention of Coronary Heart Disease: Meta-Analysis of Randomized Trials,” British Medical Journal, Vol. 321, 2000, pp. 983-989. doi:10.1136/bmj.321.7267.983

[30] J. Sheperd, G. J. Blauw, et al., "Pravastatin in Elderly Individuals at Risk of Vascular Disease (PROSPER): A Randomized Controlled Trial,” The Lancet, Vol. 360, No. 9346, 2002, pp. 1623-1630. doi:10.1016/S0140-6736(02)11600-X

[31] O. Nanni, D. Amadori, C. Lugaresi, F. Falcini, E. Scarpi
E. A. Saragoni and E. Buiatti, "Chronic Lymphocytic Leukaemias and Non-Hogkin's Lymphomas by Histological Type in Farming-Animal Breeding Workers: A Population Case-Control Study Based on a Priori Exposure Matrices,” Occupational \& Environmental Medicine, Vol. 53, No. 10, 1996, pp. 652-657. doi:10.1136/oem.53.10.652

[32] T. Zheng A. Blair, Y. Zhang, D. D. Weisenberger and S. H. Zahm, "Occupation and Risk of Non-Hodgkin's Lymphoma and Lymphocytic Leukemia,” Journal of Occupational \& Environmental Medicine, Vol. 44, No. 5, 2002 , pp. 469-474. doi:10.1097/00043764-200205000-00015

[33] L. R. Derogatis, "Symptom Checklist 90 - Revised,” NCS Assessments, Minneapolis, 1977.

[34] M. W. Ketterer, “Denial Specific to Friedman’s Pathogenic Emotions in Jenkins Activity Survey Type A and Angiography-Referred Males,” Psychosomatics, Vol. 33, No. 1, 1992, pp. 72-80.

[35] M. W. Ketterer, W. R. Lovallo and M. A. Lumley, "Quantifying the Density of Friedman's Pathogenic Emotions (Aiai)," International Journal of Psychosomatics, Vol. 40, No. 1-4, 1993, pp. 22-28.

[36] D. Waterhouse, W. J. Carmen, D. Shottenfeld, G. Gidley and S. McLean, "Cancer Incidence in the Rural Community of Tecumseh, Michigan: A Pattern of Increased Lymphopoietic Neoplasms," Cancer, Vol., 77, No. 4, 1996, pp. 763-770. doi:10.1002/cncr.1996.2820770402

[37] M. W. Ketterer, G. Mahr and A. D. Goldberg, "Psychological Factors Affecting a Medical Condition,” Journal of Psychosomatic Research, Vol. 48, No. 4-5, 2000, pp. 357-368. doi:10.1016/S0022-3999(00)00099-4 